\title{
REPORTS
}

\section{Ndanda Leper Camp, Tanganyika Territory. Annual Report 1935.}

M. Thecla Stinnesbeck.

We started the year 1935 with 190 in-patients. During the year 40 old patients returned and 130 new patients were admitted.

The number of discharges was 78: 16 patients died, 31 ran away and 31 were discharged, 9 of them cured, the others were put off treatment. In December 1935 the total was 282 in-patients.

Many of the new patients were first treated for hookworm,' bilharziosis, yaws etc., after which their general health improved.

Treatment. Hydnocreol and Alepol were given intramuscularly twice a week. The average dose given was up to $5 \mathrm{cc}$. hydnocreol and $5 \mathrm{cc}$. alepol $6 \%$. Daily washings of the body with kerosene were performed.

Hydnocreol injections were given to 160 patients: 65 nodular, 54 mixed, 8 active nerve cases, 33 children, of which 5 were nodular, and 28 nerve cases.

Alepol injections were given to 165 patients, all nerve cases.

The age of the patients is as follows:

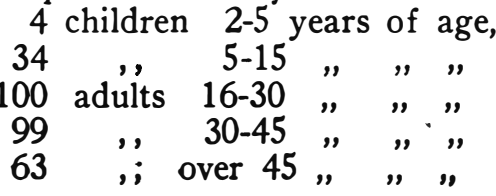

Duration of treatment:

37 patients under 3 months,

$\begin{array}{rll}59 & , & \text { for } 3 \\ 73 & \text { " for } 3-6 & \\ 156 & \text { " } & \text { for } 6-11\end{array}$

The results obtained with these 288 patients, who were under treatment for at least 3 months are :

16 died,

22 worse,

42 stationary,

122 improved,

77 much improved,

9 clinically cured. 
The dietailed results according to the duration of treatment are:

\begin{tabular}{lrrrr} 
& \multicolumn{2}{c}{3 months } & $3-6$ months & $6-11$ mo \\
died $\quad \ldots$ & $\ldots$ & 4 & 5 & 7 \\
worse $\ldots$ & $\ldots$ & 4 & 9 & 9 \\
stationary & $\ldots$ & 8 & 19 & 15 \\
improved & $\ldots$ & 26 & 49 & 47 \\
much improved & 5 & 30 & 42 \\
clinically cured & 0 & 2 & 7
\end{tabular}

Deaths : 16.

6 deaths were due to leprotic cahexia,

$4, ", "$ pneumonia

2 , " , ", hookworm

2 , " " , poisoning by native drugs.

Worse : patients 22 :

1 slight nerve case,

14 advanced nerve cases,

1 beginning nodular case,

6 advanced nodular cases.

Improved : patients 122 . The patients complained less of nerve pains, wounds closed, raised patches flattened, dry skin began sweating and their general health became better. 13 patients improved after severe lepra reaction.

Much improved: patients 77 . In some cases the nodules had almost gone, anaesthesia partly gone, sweating sometimes returned and wounds closed. Many who were unable to do hard work are now working hard in their fields. Many helped in the building of the dispensary and are none the worse.

Clinically cured: patients 9. They were all nerve cases, 5 of them children.

It might be worth while to give a list of the results, grouping them under hydnocreol and Alepol treatment.

\begin{tabular}{|c|c|c|}
\hline $\mathrm{H}$ & Anocre & Alepol \\
\hline died $\quad \ldots \quad \ldots$ & 10 & 4 \\
\hline $\begin{array}{lll}\text { worse } & \ldots & \ldots\end{array}$ & 8 & 14 \\
\hline stationary $\quad \ldots$ & 10 & 32 \\
\hline improved $\quad \ldots$ & 65 & 57 \\
\hline much improved & 46 & 31 \\
\hline clinically cured & 8 & 1 \\
\hline & 147 & 139 \\
\hline poisonings $\quad \ldots$ & - & 2 \\
\hline $\begin{array}{c}\text { under } 3 \text { months } \\
\text { treatment }\end{array}$ & 13 & 24 \\
\hline & 160 & 165 \\
\hline
\end{tabular}

Kerosene rubbing. 45 cases of nerve leprosy, who were under treatment with Alepol were daily rubbed with kerosene from head to foot for a period of 2-4 months. It was interesting to observe the raised patches flattening, some cases after 2 months.

I leave the comparative results of hydnocreol and Alepol treatment open to criticism. We obtained better results with Alepol this year 
than the previous years. I suggest it might be due to the higher concentrated solution of $6 \%$.

Bacteriological examinations. Only nasal smears were taken. We were astonished to get so many patients negative, who were positive the previous year. The positive percentage was diminished from 34.5 to $15 \%$. I doubt about this good result. It is possibly due to faulty circumstances, for instance, during the dry season the nasal discharges might be less than during the cold and raining season. We will control the patients again.

The new dispensary with a large hall for dressing wounds etc., is almost finished. We have now a fine airy dispensary consisting of four rooms. The largest room is for the injections and is divided by a wall for the males and females, a laboratory, a consultation room and a smaller room, which is used for an office. I wish to renew my grateful thanks to the B.E.L.R.A., for the grant given for the building.

My hope to get 100 leprous children is not yet realized. It takes time till African natives have confidence in European treatment and entrust their children to us.

\section{Bunyonyi Leper Colony, Uganda.}

Report for 1935.

\section{Dr. R. T. S. Goodchild reports :-}

The year 1935 has been a successful one in that the general health and contentment of the leper population has been maintained at a high level. The epidemics common in the country have not affected the Island, with the exception of four cases of cerebro-spinal meningitis, one of which died. This disease has been prevalent in the surrounding district.

A certain number of new cases have been admitted and at the close of the year the total number of lepers resident on the Island was 502, of which 181 were men, 140 were women and 181 children under 16 years of age. There has been a certain amount of coming and going, as in previous years, between the Island and the lepers' own villages.

The children in the leper school now number 130, and a high standard of efficiency is maintained by Miss Langley and the native staff-untainted and lepers.

The programme of rehousing the whole population in permanent huts has had to be brought to a standstill for lack of funds. About a quarter of the total population are adequately housed in the huts erected in 1934 and in the first month of 1935. The remainder are still living in grass huts, of which many are in a state of partial or complete collapse. Unwilling as we have been to do so, we have been compelled to spend money on the rebuilding of 40 grass huts, as many lepers were literally without a roof to their heads. About 60 more are urgently needed unless the programme of building permanent huts of brick can be recommenced immediately. About 110 permanent huts are required as soon as possible. 
Financially we have balanced the budget, but only at the cost of drastic reductions in expenditure on such items as meat for the lepers, and aid to crippled lepers for food. Of the $£ 150$ granted by the Native Administration about $£ 50$ was expended in continuing last year's building programme for the first six weeks of the year: the remainder has been used for vital services-repairs and upkeep etc. The $£ 350$ granted by the B.E.L.R.A., for maintenance has been used in current expenses-native staff, transport, customs, housekeeping and travelling. The $£ 50$ granted by the B.E.L.R.A., for building is about to be expended on building three permanent houses for senior untainted native staff. The remainder of the income of the colony is drawn from Mission sources.

The success of the colony as a public health measure is evident: very few cases of leprosy are seen in the district or in the Kabale clinics. The lepers themselves are in better general health and in many cases the disease is markedly improved. Our chief need, as may be seen from the above report, and is obvious if the Colony be visited, is for increased financial aid for permanent buildings.

\section{Kenya Colony and Protectorate.}

\section{Medical Department Annual Report for 1934.}

Three hundred and forty-five cases of leprosy were under treatment during the year. These figures, having regard to the facts that about another thousand cases were seen at out-patient dispensaries in one district alone, and that there must be many other cases which have never come to our notice, might be thought to give no indication of the amount of accommodation that we have at our disposal for the treatment of cases of this disesase.

To a certain extent it is undoubtedly true that the number of cases which we treat is determined by the accommodation at our disposal, but it is equally true, I think, that if there had been a startlingly large number of cases of this disease requiring hospitalisation we should by this time have had more beds at our disposal, for sooner or later, an irresistible demand is usually met at least to some degree. There has, however, been no such great demand for treatment. Against this fact it might, however, be argued that there has been no demand because we have been unable to show that we can do much to ameliorate the disease by specific methods of treatment, and to such an argument it might indeed be difficult to supply an answer, for very consistently the reports of Medical Officers concerned in the treatment of leprosy are to the effect that it is extremely doubtful whether specific therapy is of much value in more than a very small percentage of cases. Nevertheless, the prestige of European medicine as a whole is now so great among Africans that I feel sure that if the incidence of the disease were high we should see many more cases, while as it is, except in a few areas, the number of cases which apply for treatment is very small.

(Experience in India shows that in many places the incidence of leprosy was supposed to be low until special clinics were opened, surveys conducted, and propaganda carried out. These measures soon showed up a very high incidence.-Editor.) 

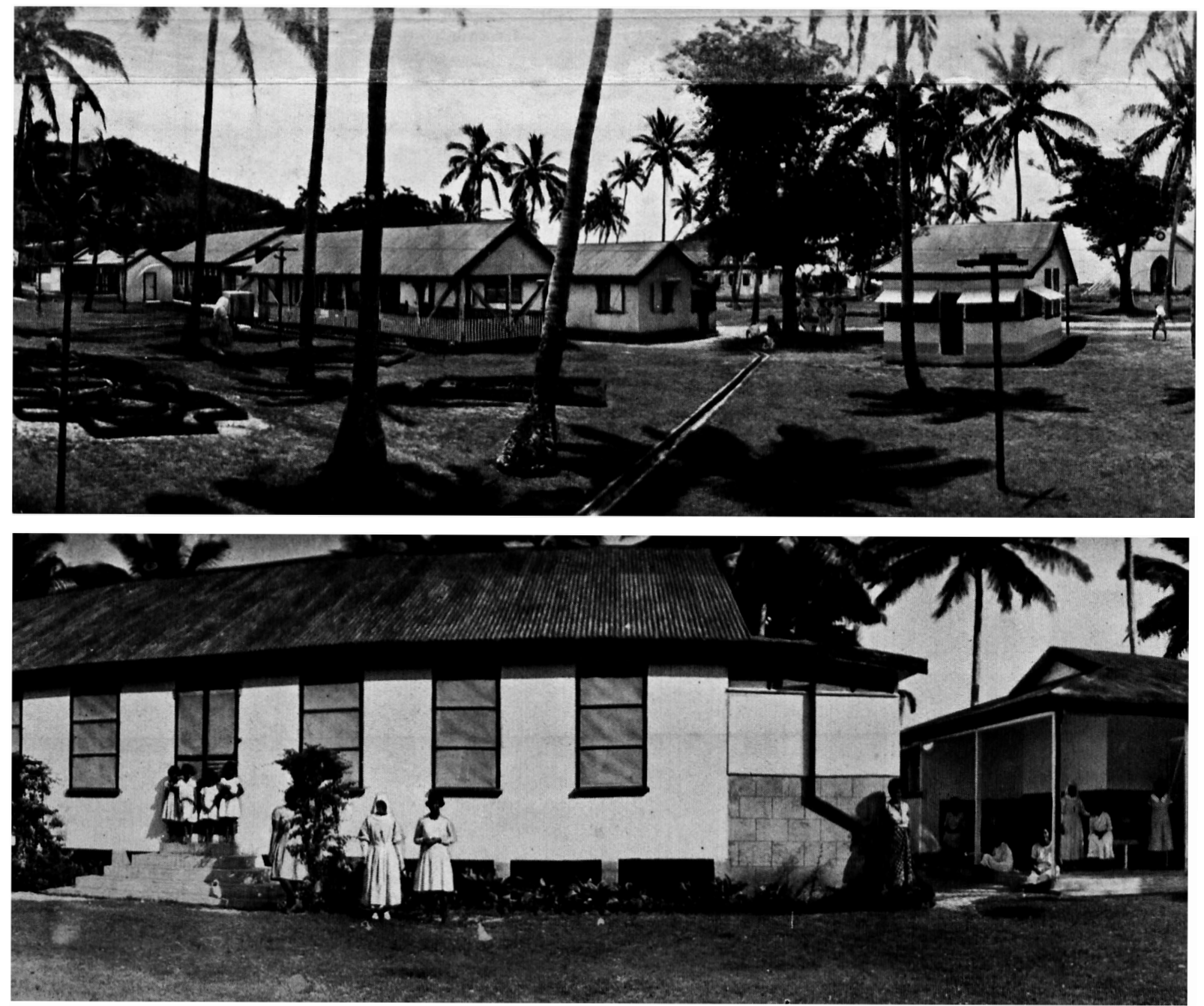

LEPIER SETTLEMENT, MAliOGAI, FIJI--'TOF) MEN's Compound (BotTom) llomen's Compocnd. 


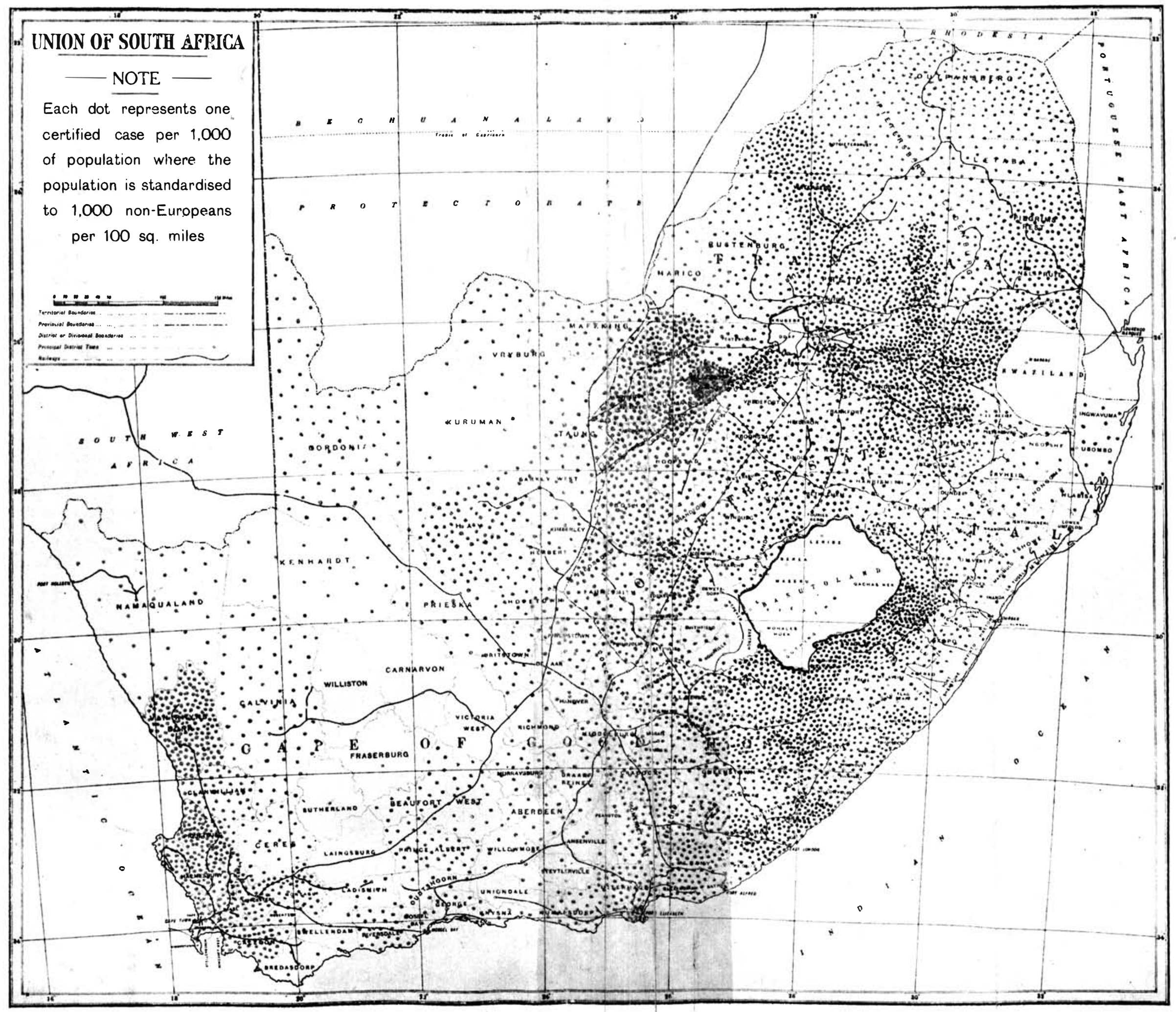


Union of South Africa. Annual Report of the Department of Public Health. Year ending June, 1935.

Tables G (i) and G (ii) indicate the position at the close of the year. It will be seen that a total of 2,144 patients were in the five institutions; 1,605 were probationally discharged; the number of cases in the institutions has decreased by 11 as compared with last year. While the number of Bantu patients still remains high, the European and mixed coloured cases have maintained a low level which was reached about five years ago after a period of consistent diminution. This is a very satisfactory state of affairs if it is remembered that the provisions of the Leprosy Repression Act of the Cape Colony, 1884, were by no means vigorously enforced until very late in the nineteenth century.

In the case of the Bantus, the high number of patients in our institutions is cause for neither alarm nor disappointment, as this is mainly due to early diagnosis. It has always been realised that the success of the Department's policy of compulsory segregation depended largely upon early diagnosis, but only since the establishment of medical schools in the Union has it become possible to ensure in a practical way the recognition of the disease in its earlier stages. The demonstrations arranged at the Pretoria Leper Institution for parties of students from the Universities of Capetown and Witwatersrand and the post-graduate courses arranged for district surgeons in connection with these universities, are probably largely responsible for the earlier diagnosis of the condition. There has been a reduction during the past decade of the average duration of the period between onset of disease and admission into an institution, from eight to six years, and with it a very considerable increase in the number of early cases admitted.

On account of these early cases our percentage of discharges has been maintained in spite of an increasing population of advanced cases of the nodular type; these cases, which ten years ago formed about one tenth of the institution population, now represent approximately 30 per cent. of the inmates.

The probationally discharged cases are kept under surveillance for a period of six years after discharge and the cases which have successfully passed through this period without recrudescence of symptoms now number 1,909.

In the report for the year ended 30th June, 1934, a map showing the relative incidence in the non-European population for the period 1900-1930 was included. In this map each dot represented one case per 10,000 of population, but as it was felt that those unacquainted with the uneven distribution of the population in this country may inadvertently draw erroneous conclusions, on the suggestion of Dr. A. Pijper, a member of the Leprosy Advisory Committee, it was decided to publish the accompanying revised map-opposite page 124-in which the population is standardised and each dot represents one case per mille per 100 square miles, thus a small comparatively thickly populated district with a low incidence, e.g. Capetown with an incidence of .069 per 1,000 p.a., will no longer compare unfavourably with larger but less thickly populated districts with a more or less similar incidence, e.g. Barberton and Pilgrims Rest in the Transvaal .068 
and .076 p.a. respectively. The new figure for charting was obtained thus :-

$$
\text { Incidence per } 1,000 \times \frac{\text { Area in square miles }}{100}
$$

thus the incidence in Capetown for the period under review is represented by 10 dots, in Barberton by 98 dots and in Pilgrims Rest by 129 dots, giving a true representation of the relative incidence of the disease in that the spacing of the dots is similar in districts of similar incidence.

This map represents some definite features which at present are difficult to explain but which nevertheless call for a short discussion. The relative incidence of leprosy during the period under review was greatest in the thickly populated agricultural areas round the Cape and that part of the Union which lies to the East of longtitude 25. This appears in distinct contrast to the complete absence of cases in the Karroo. While the low rainfall may present itself as the obvious explanation for the absence of leprosy in the Karroo, the very low incidence in the Natal coastal belt does not bear out the converse as this happens to be the area of greatest rainfall in the Union.

The District of Klerksdorp is prominent for its very high incidence. It must be explained, however, that this is due to the establishment of a refugee camp in the area during the Anglo-Boer War. There appears to be no obvious reason why the Districts of Vereeniging and Waterberg, and, to a lesser degree, Ventersdorp and Piet Retief in the Transvaal should not conform with their neighbours. The southern districts of the Free State bounding on Basutoland present a similar problem; so does the sparsely populated Van Rhynsdorp District of the Cape with its high incidence, and in contrast the thickly populated area between the Swartberg Range and the South Coast.

It is also noteworthy that on this map there appears to be no association between leprosy and other endemic diseases which tend to undermine the constitution and lower the resistance of the population, e.g. malaria and bilharzia. At this stage it is difficult to explain these and other anomalies. It is probable that the issue is obscured by our having reviewed too long a period on the same map, as it is possible that a wave of infection has spread from the Cape into a virgin soil and that the crest of the wave is reflected at various points. Broadly speaking the one consistent feature appears to be association between the density of the population and the incidence of the disease, with the Natal coastal belt as a notable exception to this generalisation.

Table G (i).-Leper Institutions : Patients therein on 30Th JUNE, 1935.

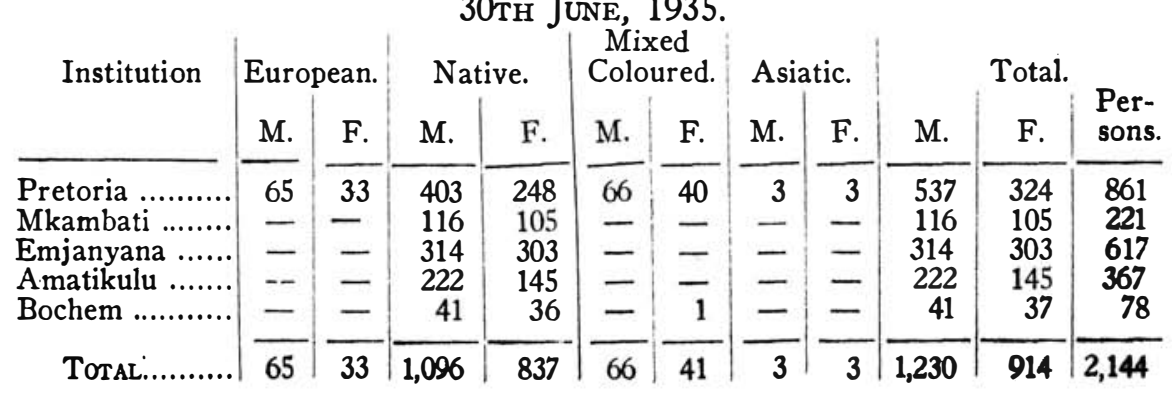


Table G (ii).-Leprosy: Cases remaining in their Own Homes ON 30Th JUNE, 1935.

\begin{tabular}{|c|c|c|c|c|c|}
\hline & \multirow{2}{*}{$\begin{array}{l}\text { Certified } \\
\text { and } \\
\text { Awaiting } \\
\text { Removal } \\
\text { to Leper } \\
\text { Institution. }\end{array}$} & \multirow{2}{*}{$\begin{array}{c}\text { Home } \\
\text { Segregated. }\end{array}$} & \multicolumn{2}{|c|}{$\begin{array}{l}\text { Probationally Discharged } \\
\text { from Leper Institutions. }\end{array}$} & \multirow[b]{2}{*}{ Total. } \\
\hline & & & $\begin{array}{l}\text { Stild under } \\
\text { Surveillance. }\end{array}$ & $\begin{array}{c}\text { Released } \\
\text { from } \\
\text { Surveillance. }\end{array}$ & \\
\hline \multirow[t]{2}{*}{ 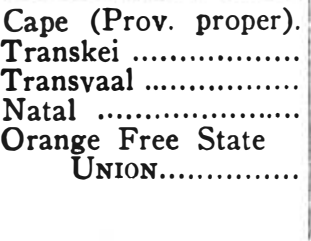 } & $\begin{array}{l}-7 \\
1 \\
-\end{array}$ & $\begin{array}{r}2 \\
2 \\
1 \\
-\end{array}$ & $\begin{array}{r}157 \\
530 \\
517 \\
308 \\
93\end{array}$ & $\begin{array}{l}385 \\
530 \\
486 \\
396\end{array}$ & $\begin{array}{r}544 \\
1,069 \\
1,005 \\
704\end{array}$ \\
\hline & 8 & 5 & 1,605 & 1,909 & 3,527 \\
\hline
\end{tabular}

\section{Ngomahuru Leprosy Hospital, Southern Rhodesia.}

The following is abstracted from the Report for 1935 :

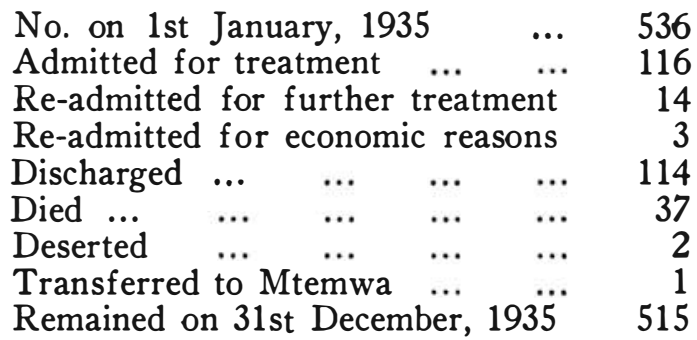

The total number of cases treated is 669 , as compared with 635 for 1934 .

Personally I have no doubt whatever of the value of iodised esters in the treatment of leprosy. I admit that there are a few cases who show no improvement whatever with the iodised esters, and they are not all cases of poor physique. Cod liver oil is of great help in cases of poor general physical condition.

In Southern Rhodesia many early cases prove to be abortive, and are emphatically not suitable for admission to a leprosy hospital. In these cases, in my opinion, no specific treatment is required, unless the patient shows signs of becoming worse.

In fairly advanced neural and mixed cases, iodised esters have effected remarkable improvements, nodules, infiltrations, maculae and anaesthesia having been caused to disappear entirely.

A few advanced nodular cases have improved considerably, both in appearance and as regards microscope examinations, but I believe that the majority of such cases are hopeless. Being the main transmitters of the disease, they must be kept segregated.

From the point of view of the patient, it is almost imperative to give treatment by injections. It would be impossible to keep patients in hospital without treatment. They demand it : without it they would desert.

Travelling expenses for the Medical Superintendent have been made available, and most of the discharged patients have been 
examined at the Headquarters stations of the Native Commissioners in the district, except at Gutu, which has yet to be done. Chibi discharges were sent here for examination, as opportunity arose, this method being more convenient for the Native Commissioner. Of 62 so examined, only 2 were brought in, requiring further treatment, a very satisfactory state of affairs.

The issue of Governor's Warrants for detention have been suspended-a great step forward.

\section{Leprosy in Nyasaland.}

The Director of Medical Services reports as follows:-

"There are in this country 12 clinics all administered by Missions, at which lepers are treated either as in-patients or out-patients or both. All of them receive money grants from Government in proportion to the number of cases treated.

Arrangements in regard to staff, housing and maintenance of patients at the various clinics vary considerably. Some have a doctor in charge, with a qualified nurse and native subordinates; the majority are in charge of a qualified nurse. Housing varies from daub and wattle huts to well-built red brick structures.. At some centres the lepers have been encouraged to grow their own food supplies; at others food is bought in bulk by the Mission concerned. One or two of the Missions have started schools for the lepers, and though the majority of them may not be able to gain much knowledge from the instruction given, it is of great benefit to them to have their interest aroused and their minds distracted from their unfortunate physical condition.

The numbers under treatment at the leper centres per quarter were on an average as follows:-

Bandawe 64. Domasi 25, Likoma 17, Likwenu 63, Livingstonia 7, Loudon 17, Malamulo 49.25, Malindi 31.25, Mkhoma 8, Mua 64.50, Mwami 39.25, Utale 97.50.

In addition to the cases maintained and treated by the Missions, 88 male and 18 female lepers were treated as out-patients by Government medical officers. 